\title{
ESTUDOS
}

\section{A avaliação institucional da Unesp: um processo de construçãa coletiva}

Thereza Marini

Palavras-Chave: avaliação institucional; indicadores;

Comissão Permanente de Avaliação Acadêmica (CPAA); modelos estatísticos.
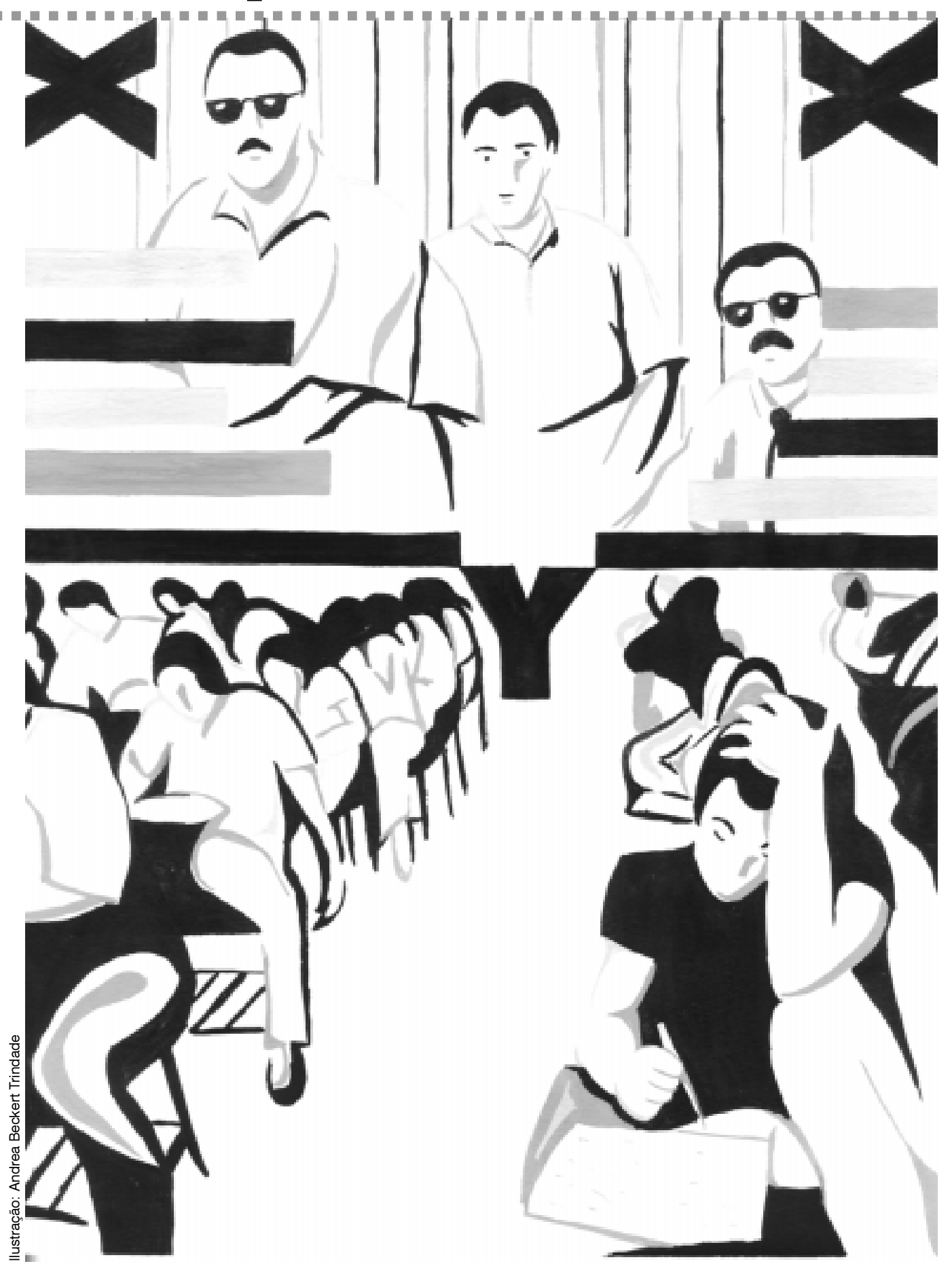
R

elato interpretativo do

processo de avaliação institucional

da Universidade Estadual Paulista

(Unesp), com ênfase na

metodologia do seu

desenvolvimento. Mediante um

trabalho coletivo numa rede de

relações democráticas, a

avaliação realizou-se por um

processo valorativo das atividades

relevantes às funções-fim da

instituição, à vista de seus

recursos e de seu contexto

sociohistórico. Iniciada com a

avaliação dos seus 207

departamentos agrupados

segundo seus campos de

pesquisa e ensino (Ciências

Humanas, Biológicas e Exatas), a

experiência deflagrou "uma

atividade particular, contínua e

cíclica, incorporando vários

métodos e envolvendo várias

fases e operações nos seus 15

campi e 24 unidades universitárias

no período 1991-1994. As

informações foram obtidas de indicadores selecionados pelos

departamentos das unidades

universitárias, tendo em vista

objetivos e princípios previamente definidos. É em consonância com estes que se pode afirmar que a avaliação da Unesp contribuiu para o desenvolvimento de um processo de reflexão e debate favorável à construção de uma autoconsciência institucional e de uma identidade explícita, além de fornecer subsídios para a tomada de decisões que favoreçam a implementação de um projeto de universidade definido

coletivamente.

\section{Consideracões sobre o conceito de avaliação institucional}

O propósito deste artigo é fazer um relato interpretativo, um exercício de reflexão da experiência vivida no processo que a Universidade Estadual Paulista (Unesp) vem desenvolvendo com a sua avaliação institucional.

Dada a multiplicidade de fatos, idéias e formas de trabalho desencadeadas no decorrer do processo avaliatório, faz-se necessário balizá-los pela relevância e alcance que têm para descrever uma avaliação institucional que, como tal, perpassa toda a universidade, tendo por objeto de análise valorativa as suas funções-fim e por suporte os seus recursos financeiros, humanos, físicos, didáticos e administrativos. Para delimitar o campo desta abordagem nada melhor, a meu ver, que tomar a avaliação pelo significado que foi ganhando desde o delineamento do seu processo até a sua execução. Através de um trabalho coletivo envolvendo diferentes segmentos da universidade num processo de relações democráticas, a avaliação vem se realizando como um processo descritivo-valorativo das atividades acadêmicas relevantes da instituição, propiciando-lhe a construção de sua autoconsciência e oferecendo-lhe subsídios para a tomada de decisões que levem ao aperfeiçoamento de seus programas e do desempenho de suas funções. ${ }^{1}$

$\mathrm{O}$ entendimento e a realização da avaliação como processo encontram ressonância em Stufflebeam (1971), que a define como "uma atividade particular, contínua e cíclica incorporando vários métodos e envolvendo um número de fases ou operações".

Nessa linha de interpretação, distingue-se como primeira característica desse processo a sua natureza valorativa. A descrição da realidade traz no seu bojo o julgamento de valor, o que significa que nem todo dado pode ser tomado como indicador para uma descrição significativa da instituição num determinado tempo. Por essa razão o julgamento de valor implica a seletividade dos dados sejam eles ações, processos, programas, resultados, condições infra-estruturais, dentre outros.

O julgamento de valor é baseado em critérios estabelecidos previamente e que expressam padrões e expectativas conscientes e intencionalmente ordenados em

\footnotetext{
As citações de autores tomadas para referendar teoricamente o conceito de avaliação aqui definido fazem parte do trabalho de David Nevo, "The Conceptualization of Educational Evaluation: an analytical review of the literature", publicado na Review of Educational Research, v. 53, n. 1, p. 117 128, spring, 1983.
} 
consonância com os objetivos da avaliação, o que permite aos avaliadores determinarem o valor relativo dos dados descritivos da instituição avaliada, tomada em sua totalidade.

Como segunda característica da avaliação está a sua capacidade de alimentar um processo de autoconsciência e de definição da identidade institucional.

Trata-se de um processo que leva aqueles que dele participam a uma leitura globalizadora da instituição pela relação que eles estabelecem entre seus objetivos e a produção acadêmica e o contexto institucional: sua história, seus condicionantes socioeconômicos e políticos e os recursos humanos, materiais, didático-científicos e financeiros de que dispõe.

Autoconsciência e identidade institucional se constroem na práxis acadêmica cotidiana. A avaliação, no entanto, abre um espaço, um tempo particular à reflexão, à discussão e ao debate dos participantes sobre o desempenho e a produção acadêmica e aponta caminhos para uma tomada de posição coerente com os fins e os meios da instituição, ao mesmo tempo em que realimenta a motivação para o engajamento nos projetos de seu aperfeiçoamento.

Finalmente, uma terceira característica da avaliação é o seu caráter instrumental que se concretiza pela realização de funções específicas vinculadas a objetivos também específicos. Na literatura e na prática da avaliação educacional, são bastante difundidas duas funções: 1) a formativa (Scriven, 1967, apud Nevo, 1983) também chamada de proativa (Stufflebeam, 1972, apud Nevo, 1983), usada para a tomada de decisões que levem ao aperfeiçoamento de um programa, de um processo, de um produto de uma instituição; 2) a somativa (Scriven, 1967, apud Nevo, 1983) ou retroativa (Stufflebeam, 1972, apud Nevo, 1983), que se presta à contabilidade da produção e dos resultados com vistas à seleção, classificação e atribuição de mérito.

A prioridade atribuída a uma ou outra dessas funções é que adjetiva a avaliação de formativa ou somativa. Via de regra, no entanto, elas não são mutuamente excludentes num processo avaliatório, podendo cada uma delas prevalecer em determinados momentos. Assim, por exemplo, na avaliação que tem por objeto primeiro o produto das atividades acadêmicas, a descrição dos resultados costuma ter por trás uma escala de prioridades vinculada a critérios de valor, que por sua vez podem corresponder à concepção de instituição, às suas potencialidades, necessidades e expectativas, etc. Nesse caso, pode-se denominar o processo avaliatório de quantiqualitativo por ultrapassar uma função meramente contábil, classificatória e comprometida com o produto e por permitir a utilização desses resultados para tomadas de decisões visando seja ao incremento da produção, seja ao seu aperfeiçoamento.

Por sua vez, a avaliação formativa, ao priorizar as provisões de informações para subsidiar a tomada de decisões, prevê a intervenção no processo ativo da instituição com o propósito de aperfeiçoar seus programas, o desempenho qualitativo de suas atividades e, quando for o caso, até o incremento da sua produção. Com essa função formativa, a avaliação baliza seus dados com critérios de excelência alinhados com os objetivos da instituição e levando em consideração o seu contexto operacional (necessidades, oportunidades e potencialidades). Essas características levam-me a identificar a função formativa com a comumente denominada avaliação qualitativa. $\mathrm{O}$ exercício desta função, por sua vez, pode recorrer ao suporte de dados quantitativos sempre que estes venham contribuir para explicar a tomada de decisões. Nesse caso, pode-se chamar de qualiquantitativa esta avaliação.

Uma terceira função da avaliação, nem sempre tratada pela literatura ou posta em prática pelos avaliadores, é a função psicológica ou sociopolítica (Crombach, et al., 1980; House, 1974, apud Nevo, 1983; Patton, 1978, apud Nevo, 1983). Seu desempenho faz crescer a autoconsciência institucional a respeito da especificidade de suas ações e das prioridades a serem definidas em face das demandas sociopolíticas, bem como estimular comportamentos individuais e relações interpessoais identificados com os propósitos e programas da instituição. A meu ver, esta função pode se compor com a função formativa facilitando-a à medida que atua junto aos sujeitos da avaliação que são os membros ativos da instituição e co-responsáveis pelo seu aperfeiçoamento.

Não obstante o processo avaliatório poder ser conduzido com o desempenho 
conjugado das três funções acima descritas, a ele pode, em contrapartida, ser atribuída, ainda, uma função administrativa (Dornbush, Scott, 1975, apud Nevo, 1983). Essa função recebe uma conotação impopular quando usada para o exercício da autoridade de quem avalia sobre os avaliados. Via de regra, a prática dessa avaliação fica a cargo de quem ocupa posto de chefia ou direção, dispensando a participação dos demais membros da instituição. Essa impopularidade recrudesce quando essa avaliação leva à premiação ou à punição.

Feita essa interpretação conceitual e funcional da avaliação, retomo a experiência em curso na Unesp. Como um processo contínuo e cíclico ela se faz pela passagem por diferentes fases que vão incorporando informações, métodos e estratégias que conjugam as funções somativa, formativa e psicológica ou sociopolítica da avaliação. No presente momento, são objeto de descrição valorativa os indicadores da produção acadêmica no ensino, na pesquisa e na extensão. A escolha desses indicadores foi feita, no entanto, num trabalho coletivo, tomando por parâmetro os critérios de relevância afinados com a natureza e os objetivos da instituição e aqueles da própria avaliação que define como seu "objetivo fundamental a construção de uma autoconsciência institucional e de uma identidade explícita". Para o alcance desse objetivo, a avaliação deve contribuir com vistas a "instaurar um processo de reflexão" e debate sobre as informações e os resultados dela decorrentes, que propiciem o delineamento da universidade que se quer e que ofereçam subsídios à tomada de decisões para a implemen-tação de projetos que façam dessa universidade visualizada e desejada uma realidade concreta. Portanto, embora o processo avaliatório da Unesp tenha tomado como ponto de partida a coleta de informações sobre a produção acadêmica, o seu ponto de chegada é, com elas, subsidiar tomadas de decisões que levem ao aperfeiçoamento da instituição, o que confere à avaliação também a função for-mativa. O caminhar de um ponto a outro é feito pelo exercício da reflexão, do debate, do engajamento individual num trabalho coletivo, numa trama de relações que envolve toda a universidade. A reflexão e o debate é que levam à sinalização de no- vos caminhos. Sem eles não se vai a lugar algum, ou se deixa lugar para o autoritarismo.

Dado o seu caráter contínuo e cumulativo, fechado esse ciclo, tomar-se-á a qualidade do desempenho acadêmico como objeto da descrição valorativa. Aqui também o processo incorporará dados quantitativos sempre que necessários para contextualizar e/ou explicar as informações que se pautarão pelos mesmos critérios e objetivos já aqui registrados.

Essa opção por trabalhar articuladamente as funções somativa e formativa na avaliação institucional da Unesp encontra respaldo teórico em proposições de cientistas sociais, quando abordam a questão da quantidade-qualidade na área da metodologia científica. Ilustrando com algumas referências tomo, de início, uma citação de Michel Thiollent sobre a questão do reducionismo em sua síntese da diversidade de abordagens metodológicas das ciências sociais:

...não podemos resumir numa oposição
qualitativo versus quantitativo (...) podemos
distinguir uma pluralidade de enfoques que
dão privilégio quer aos aspectos qualitati-
vos, quer aos quantitativos. Do ponto de
vista do ideal geral da ciência, pensamos
que uma articulação dos dois tipos de as-
pectos é mais satisfatória. Mas, dependen-
do do assunto e da abrangência da obser-
vação, certas pesquisas são principalmen-
te qualitativas ou principalmente quantita-
tivas (Thiollent, 1984, apud Oliveira, 1996,
p. 46).

Numa concepção dialética da história, assim se manifesta Gramsci (1966, p. 50 ):

Dado que não pode existir quantidade sem qualidade (economia sem cultura, atividade prática sem inteligência, e viceversa), toda contraposição dos dois termos é racionalmente um contra-senso...

Nessa mesma linha, em trabalho recente, Santos Filho (1995, p. 51) trata as dimensões quantitativas e qualitativas como inter-relacionadas, como se lê na afirmação seguinte:

... a evidência quantitativa, mesmo nas ciências naturais, não pode ser interpretada independentemente das considerações qualitativas extra-observação e extrateoria. Em síntese os métodos quan- 
titativos e qualitativos não são incompatíveis; pelo contrário, estão intimamente imbricados e, portanto, podem ser usados pelos pesquisadores sem caírem em contradições epistemológicas.

Voltando da teoria à prática, tomo como objeto de análise as fases do processo avaliatório da Unesp.

\section{As fases do processo avaliatório}

\section{0 delineamento do processo de avaliação}

A Unesp começou a delinear o seu processo de avaliação institucional ora em curso a partir de 1989, quando o então presidente da Comissão de Ensino, Pesquisa e Extensão (Cepe), professor Antonio Cesar Perri de Carvalho, pelo Ofício-Circular no 39/89, constitui uma comissão para, com a participação de todas as unidades universitárias, elaborar a definição de critérios e os rumos dessa avaliação.

A década de 80 caracterizou-se como um período de pressões da sociedade sobre a produção e desempenho das universidades públicas em face das demandas sociais, acrescendo-se a esse reclamo a crise financeira na qual elas se encontravam e em que, aliás, continuam mergulhadas. Nessas circunstâncias, a Unesp se alinha a outras universidades que têm assumido a avaliação institucional como uma via que leva ao conhecimento objetivo e sistemático da sua produção e da qualidade do seu desempenho em face das suas funções específicas. Nessa concepção, a avaliação se faz necessária para tomadas de decisões que impliquem, quando for o caso, a revisão dessas funções e mudanças seja na sua estrutura administrativa, nos seus objetivos, conteúdos e métodos científico-pedagógicos, seja em suas relações com a sociedade cujas demandas cumulativas são cada vez mais complexas e variadas, e até então alheias à universidade, colocando em questão a sua identidade.

A Unesp é a mais nova das três universidades públicas do Estado de São Paulo. Possui 23 anos e nestas duas décadas vem se consolidando como a "universidade de todo o Estado de São Paulo" com seus 15 campi e 24 unidades universitárias por eles estendidos.
Como universidade constituída por muitos campi e criada pela reunião de escolas e faculdades até então funcionando como institutos isolados, a Unesp instaurou uma estrutura pedagógica, científica e administrativa que vem sustentando as redes de relações que buscam garantir ao mesmo tempo a pluralidade pelas diferenças e diversidade de seus campi e a unidade pela convergência das funções para fins comuns.

Cabe aqui tomar um pensamento de Habermas sobre as universidades modernas:

\begin{abstract}
As universidades modernas incorporam funções múltiplas e convergentes (...) assumidas por diferentes grupos de pessoas em diferentes lugares institucionais e com diversos pesos relativos. A consciência corporativa dilui-se assim na consciência intersubjetivamente partiIhada de que uns fazem coisas diferentes dos outros, mas que, todos juntos, fazendo de uma ou outra forma trabaIho científico, preenchem, não uma função, mas um feixe de funções convergentes (Habermas, 1987, apud Dias Sobrinho, 1995, p. 16).
\end{abstract}

Se na concepção de Habermas as funções múltiplas e divergentes caracterizam as universidades modernas independentemente do arranjo espacial em que se situam, no caso da Unesp essas funções ganham uma dinâmica própria, em razão mesmo do arranjo espacial dos seus campi em diferentes cidades, marcando a sua presença em todas as regiões do Estado de São Paulo e com elas interagindo, em condições específicas de produção da pesquisa, da transmissão do conhecimento e dos serviços à comunidade.

Sendo uma instituição social e historicamente situada, a Unesp, como toda universidade consciente de suas funções específicas, não é uma realidade pronta e acabada, mas sim em permanente processo de construção que é engendrado pelas redes de relações no interior das unidades e destas entre si, numa busca de respostas às pressões advindas das transformações da sociedade contemporânea. É nessa direção que apontam as proposições de Maria Encarnação B. Spósito (1996) em "Novas Formas de Atuação" numa sociedade que vive hoje um intenso processo de globalização da economia e mudanças 
nas relações sociais e valores culturais. No seu artigo, a autora vincula a diversidade e a convergência de funções da Unesp, bem como seu arranjo territorial, como condições privilegiadas para a sua atuação em projetos, de iniciativa pública ou privada, que atendam às demandas das cidades e regiões onde estão localizados os seus campi.

Ao deflagrar em 1989 a sua avaliação institucional, a Unesp envolveu todos os seus campi com suas diferentes unidades universitárias num processo de participação democrática crescente que, coordenado pelo Cepe, iniciou-se com reuniões, discussões e debates no interior dos departamentos e pareceres no nível das congregações.

Por tratar-se da primeira vez que as unidades eram chamadas a pensar, discutir e propor a sua auto-avaliação, esse primeiro momento do processo foi vivido em níveis diferentes de participação pelos campi, mesmo porque não havia consenso sobre a necessidade da avaliação e, pode-se dizer, havia até mesmo um certo temor sobre as possíveis conseqüências de caráter meritocrático e punitivo que poderiam dela resultar. Alimentando ainda esse clima, poderiam estar algumas interpretações, evidentemente não generalizáveis, apoiadas numa certa concepção de autonomia universitária não sujeita ao julgamento do seu desempenho pela sociedade que a mantém.

Evidentemente, é natural essa pluralidade de comportamentos que se manifestam na trama de relações complexas e marcadas por diferentes entendimentos e práticas da vida acadêmica. No entanto, são essas mesmas diferenças que explicam as contribuições legítimas e significativas para a definição dos princípios e objetivos norteadores da avaliação, bem como das estratégias e condições de sua realização.

Com esses subsídios, o Cepe deliberou que, no conjunto, o processo avaliatório deveria envolver todos os segmentos docentes, técnicos e administrativos, tomando-se, contudo, o departamento, célula básica das unidades universitárias, como ponto de partida da avaliação. De julho a novembro de 1992 , com uma comissão formada no interior do Cepe, foram discutidos os princípios e objetivos norteadores do processo avaliatório e definidos, a título de sondagem, 49 indicadores referentes às atividades acadêmicas com seus respectivos pesos. Foram ainda testados dois modelos estatísticos para o tratamento dos dados após a sua coleta.

O primeiro - Análise de Dependência, criado pelo professor José Antonio Cordeiro, do Instituto de Biociências, Letras e Ciências Exatas de São José do Rio Preto, permite comparar os departamentos de uma mesma área de conhecimento, no que eles se diferenciam e analisar as atividades predominantes em cada departamento, e de uma forma global as de uma área de conhecimento.

O segundo - Modelo Hierárquico Dinâmico, de autoria do professor Anibal Sant'Anna, da Fundação Getúlio Vargas de São Paulo, compara a força de trabalho docente com a sua produção acadêmica. Os resultados mostram se o departamento tem uma produção compatível, superior ou inferior à prevista e à sua força de trabalho, num dado período.

Como designa o seu próprio nome, esse modelo atende ao propósito da avaliação institucional da Unesp, qual seja, o da construção contínua e permanente do seu processo, o qual se aperfeiçoa à medida que acumula informação confiável, que novas medidas e novos indicadores relevantes são por ele incorporados ou outros menos significativos são revistos.

Com esse propósito, avaliação e meta-avaliação caminham juntas numa relação em que a segunda oferece elementos para que a primeira alcance progressivamente os seus objetivos.

Com esses elementos e, por escoIha da Cepe, um projeto-piloto da avaliação foi aplicado na Faculdade de Ciências e Tecnologia do campus de Presidente Prudente e no Instituto de Biociências, Letras e Ciências Exatas do campus de São José do Rio Preto, ambas as unidades com departamentos nas três áreas do conhecimento: Exatas, Humanas e Biológicas.

Aos blocos de indicadores referentes às atividades de ensino, pesquisa e extensão nessas áreas, foram determinados, respectivamente, os pesos 40, 20 e 20.

Os resultados dessa aplicação piloto mostraram a necessidade da ampliação do número de indicadores, bem como a revisão dos pesos a eles atribuídos, considerando-se as respectivas áreas de conheci- 
mento. Quanto aos modelos estatísticos experimentados, ambos foram aprovados pelo Cepe no final de 1992 e passaram a compor o sistema metodológico da avaliação da Unesp em sua formalização.

\section{A formalização do projeto de avaliação}

Essa formalização se iniciou com um conjunto de ações deliberativas do Cepe das quais resultaram os objetivos e os princípios gerais da avaliação.

\section{Os objetivos da avaliação}

O processo de avaliação acadêmica teve por objetivo fundamental a construção de uma autoconsciência institucional e de uma identidade explícita. Para isso, deverá:

1) contribuir para instaurar um processo de reflexão e debate, que conduza ao delineamento de um projeto de universidade;

2) fornecer subsídios para a tomada de decisões que favoreçam a implementação do projeto de universidade definido;

3) considerar a produção da universidade em suas funções básicas (ensino, pesquisa e extensão), bem como as condições infra-estruturais que condicionam a realização dessas funções, ou seja:

a) os processos que levem à criação, preservação, organização e transmissão do saber e da cultura, através do ensino e da pesquisa;

b) o processo de formação de recursos humanos para o exercício das atividades para as quais são oferecidas habilitações e outorgados diplomas, bem como os recursos humanos preparados em seus diferentes cursos, considerando simultaneamente os fatores intervenientes, os processos, os resultados e os impactos;

c) as necessidades da comunicação entre universidade e sociedade associadamente às atividades acadêmicas que permitem contribuir com a prestação de serviços à comunidade;

d) o desempenho do pessoal técnicocientífico, quer individualmente quer coletivamente, no contexto de departamentos, institutos, unidades auxiliares, centros interdepartamentais, museus e outros; e) as condições de trabalho do pessoal docente e dos administradores (reitoria, diretores de unidades, chefes de departamentos, coordenadores de cursos), em face das ações esperadas desses diferentes agentes, tendo em vista os diferentes papéis da universidade.

\section{Os princípios gerais da avaliação}

Para atingir seus objetivos fundamentais, o processo avaliatório deveria ser operacionalizado em caráter permanente, através de comissão especial, devendo ter como parâmetros os princípios gerais seguintes:

1) Universalidade - Envolvimento de todos os departamentos, unidades universitárias, unidades auxiliares, centros interunidades, museus, conselhos de curso, docentes, pesquisadores e administradores (chefes de departamentos, diretores, coordenadores, pró-reitores, reitor e vice-reitor).

2) Totalidade - Envolvimento de todas as atividades da universidade, isto é, de ensino, pesquisa, extensão e serviço e inclusive, de maneira adequada, as administrativas. Também o próprio processo avaliatório deveria ser permanentemente avaliado e aperfeiçoado, considerando-se seu objetivo principal: produzir melhorias para o futuro.

3) Igualdade - Os aspectos básicos que devem servir para a avaliação integral da universidade. Assim, por exemplo, o ensino deveria ser avaliado como produto da ação docente, do departamento e da unidade e não apenas através do trabalho do professor.

4) Especificidade - Consideração das particularidades dos diferentes cursos, departamentos e atividades docentes, em acréscimo aos aspectos básicos que serão necessariamente avaliados. Não se pode avaliar a diversidade de maneira uniforme, mas é preciso considerar também que a diversidade não pode se converter em símbolo do único.

5) Periodicidade - Definição dos espaçamentos temporais ajustados aos diferentes segmentos, atividades e unidades da universidade.

6) Racionalidade - Não-multiplicação de procedimentos idênticos para os mesmos fins, considerando todos os docentes e pesquisadores, bem como os departamentos, como instâncias fundamentais que 
são do processo avaliatório que com eles e neles deveria ter início.

7) Transparência - Identificação precisa e objetiva do processo avaliatório, especialmente quanto aos níveis de participação de todos os envolvidos, no que concerne aos componentes da avaliação e aos resultados dela esperados.

8) Integração - Consideração de que há um mínimo que deve ser produzido, bem como um máximo que pode ser alcançado, e tendo em vista o princípio da especificidade, valorizar os processos compensatórios nos quais, dentro de determinados limites, as atividades desenvolvidas numa categoria poderiam complementar outras, em outras categorias. A universidade deveria reconhecer que no contexto de suas funções básicas, docentes, departamentos e unidades poderiam apresentar salutar variação quanto ao envolvimento com cada uma delas.

9) Retribuição - Consideração da diversidade de retornos que os processos avaliatórios poderiam e deveriam gerar, tanto para docentes quanto para departamentos e unidades, tais como a locação de recursos e aprovação de projetos.

10) Cumulatividade - A acumulação progressiva de todas as modalidades de trabalhos acadêmicos relativos aos docentes, pesquisadores, departamentos e unidades, de tal sorte que a avaliação seja traduzida num processo contínuo e não apenas em episódios e momentos. Cada docente, departamento e unidade deveriam ser encarados e avaliados mediante sua história de trabalho e não pontualmente.

\section{A constituição do Grupo de Trabalho de Avaliação Acadêmica (GTAA)}

O GTAA foi constituído em 18/2/1993 pelo Despacho no 45/93 - Cepe/SG com três conselheiros do Cepe representando as áreas de Ciências Humanas, Ciências Exatas e Ciências Biológicas, dois especialistas em avaliação, três em estatística e um em processamento de dados.

\section{A definição de indicadores de produção acadêmica}

Foi feita pelo Cepe em 31/3/1993. Totalizando o número de 110 , esses indicadores compunham seis blocos que, à ex- ceção do primeiro, integravam atividades acadêmicas, assim distribuídas:

1) Caracterização do departamento - 10 indicadores;

2) Atividades de formação - 12;

3) Atividades de ensino - 32;

4) Atividades de pesquisa - 25;

5) Atividades de extensão e serviços $-14$

6) Atividades acadêmico-administrativas -17 .

A ponderação para cada bloco de indicadores, à exceção dos do agrupamento Saúde (área de Ciências Biológicas), ficou assim determinada: Blocos 3 e 4 - 30\%; Bloco 5 - 20\%; Bloco 2 - 15\%; Grupo $6-5 \%$. Os departamentos enquadrados no agrupamento Saúde tiveram a seguinte ponderação: Blocos 3, 4 e 5 - 26,7\%; Bloco 2 - 0\%; Bloco $6-5 \%$.

\section{A seleção dos indicadores e a sua ponderação}

Dos 110 indicadores aprovados pelo Cepe, o GTAA selecionou 48 pertencentes aos seis blocos acima, como objeto de análise na primeira fase de implantação do processo avaliatório, que cobriria os anos de 1991 e 1992. A relevância de cada um desses indicadores foi definida pela ordem de prioridade a ele atribuída, variando de 1 a 3 , e pelo peso, que variou de 1 a 10. Essa atribuição de valores resultou de uma ampla discussão, envolvendo todos os membros do GTAA e tomando como referência as três áreas de conhecimento ali representadas. A ponderação final resultou da média ponderada dos pesos conferidos individualizadamente pelos membros. Em maio de 1993, o GTAA apresentou esse trabalho ao Cepe, que o discutiu e o aprovou.

\section{A avaliação nos departamentos}

Os indicadores foram organizados em uma planilha, reproduzida a seguir, a ser preenchida em cada departamento com informações numéricas a eles correspondentes. 


\section{AVALIAÇÃO ACADÊMICA UNIVERSIDADE ESTADUAL PAULISTA}
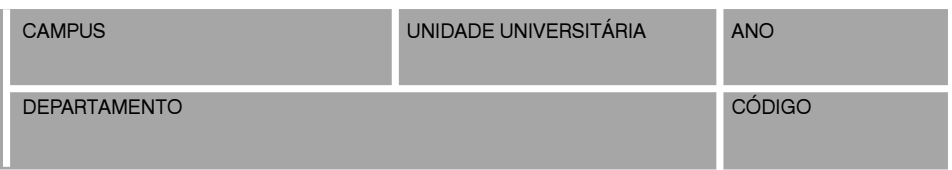

\section{IDENTIFICAÇÃO DO DEPARTAMENTO}

1.1. Percentual de pós-graduados

$\mathrm{V} 11$

1.2. Percentual de tempo parcial

V12

1.3. Percentual de afastados

1.4. Número de técnicas especializadas

1.5. Número de bolsas de pesquisa do $\mathrm{CNPq}$

$\mathrm{V} 13$

V14

1.6. Número de docentes com bolsas do PICD

V15

V16

1.7. Número de prêmios de professores

1.8. Tempo de existência do departamento (meses)

V17

1.9. Número de cursos atendidos pelo departamento

1.10. Folha de pagamento/docentes (Cr\$ mil)

V18

V19

2. ATIVIDADES RELATIVAS À FORMAÇÃO

2.1. Número de dissertações de mestrado defendidas

V110

2.2. Número de teses de doutorado defendidas

2.3. Número de concursos de livre-docência

2.4. Número de concursos para assistente

2.5. Número de concursos para titular

V21

V22

V23

V24

V25

\section{ATIVIDADES DE PESQUISA}

3.1. Número de livros e capítulos publicados

V31

3.2. Número de artigos em revistas internacionais

3.3. Número de outras publicações

3.4. Eventos organizados ou promovidos

3.5. Comunicações em congressos

3.6. Gravações e obras de arte

3.7. Enumere grupos de pesquisa sob responsabilidade do departamento

V32

V33

V34

V35

V36

4. ATIVIDADES DE ENSINO

4.1. Número de disciplinas de graduação

V310

4.2. Número médio de turmas por disciplina/graduação

4.3. Carga horária/graduação

4.4. Número médio de alunos por turma/graduação

4.5. Número de disciplinas da pós-graduação

4.6. Número médio de turmas por disciplina/pós-graduação

4.7. Carga horária/pós-graduação

4.8. Número médio de alunos por turma/pós-graduação

4.9. Número de cursos de extensão

4.10. Número de cursos de extensão

4.11. Número de cursos de especialização

4.12. Número de cursos de residência

4.13. Número de professoresna pós-graduação

4.14. Conceito CAPES dos cursos de pós-graduação

V41

V42

V43

V44

V45

V46

V47

V48

V49

V50

V411

V412

V413

V414

\section{ATIVIDADES DE EXTENSÃO DE SERVIÇOS À COMUNIDADE}

EXTER. ACAD.

5.1. Número de cursos de extensão cultural

5.2. Número de cursos de atualização

V51

5.3. Número de consultorias e assessorias

5.4. Eventos organizados para a comunidade

5.5. Museus e similares para a comunidade

5.6. Projetos-Parceria

\section{ATIVIDADES ACADÊMICO-ADMINISTRATIVAS}

6.1. Número de diretores

V52

V53

V54

V55

V34

6.2. Número de supervisores de unidades auxiliares

6.3. Número de coordenadores de curso

6.4. Número de coordenadores de grupos de pesquisa

6.5. Número de participantes nos órgãos colegiados da administração central

6.6. Número de docentes na função de assessor junto à administração superior

V61

V62

V63

V64

V65

V66 
As planilhas foram encaminhadas pelo presidente do Cepe aos departamentos via diretores das unidades, em 9/3/93. Para facilitar o seu preenchimento e ao mesmo tempo assegurar precisão e confiabilidade aos dados informativos, as planilhas foram acompanhadas de um manual de instruções detalhadas sobre o seu preenchimento e de cópias de informações já disponíveis na secretariageral da Unesp, acrescidas, no entanto, da observação "sujeito à revisão crítica".

Um ofício-circular acompanhou esse último material, enfatizando a importância da revisão e correção daquelas informações, quando fosse o caso, e encarecendo a urgência na devolução da planilha preenchida pelo departamento.

Essa fase foi bastante complicada para os departamentos que, não obstante contarem com as cópias de seus relatórios anuais de 1991 e 1992, as informações neles disponíveis eram, algumas vezes, insuficientes ou imprecisas para um rigoroso atendimento ao solicitado nos indicadores da planilha. Somaram-se a esse problema dois outros pertinentes ao próprio preenchimento: um pela forma de redação das instruções, que suscitou muitas dúvidas sobre "o que" e "como" informar certos indicadores, e outro pertinente ao não-atendimento do disposto naquelas instruções. Parte desses problemas foi resolvida pelo contato telefônico dos departamentos com o GTAA e vice-versa, e parte pela devolução de planilhas pelo GTAA aos departamentos para correções mais demoradas. Mesmo com uma terceira consulta aos departamentos, persistiram dúvidas e incorreções, fazendo os dados pouco confiáveis numa análise mais rigorosa. Em razão desses fatos, o GTAA agrupou alguns indicadores e atribuiu novas ponderações a outros. Com a devolução de 194 planilhas referentes ao ano de 1991 e 197 ao de 1992 , correspondendo à quase totalidade das que foram enviadas, o GTAA, rediscutindo a natureza das atividades dos diferentes departamentos e atendendo ao pedido de autoenquadramento dos mesmos pelo seus membros, realocou-os em quatro áreas de conhecimento, como é mostrado abaixo:
O tratamento das informações constantes das planilhas foi feito pelos dois modelos estatísticos rapidamente apresentados na fase do delineamento do processo de avaliação: Análise de Dependência (Anadepe) e Modelo Hierárquico Dinâmico. Da aplicação de ambos, bem como do trabalho do GTAA na condução do processo avaliatório nas suas fases de formalização e de execução, chegou-se às constatações e apontamentos que fazem parte do Relatório Final encaminhado pelo grupo de trabaIho ao Cepe, em fevereiro de 1994.

\section{Resultados e apontamentos para 0 aperfeiçoamento da avaliação}

$\mathrm{Na}$ impossibilidade de trazer para este texto todas as interpretações dos resultados obtidos com a metodologia aplicada no transcorrer do processo avaliatório, tomo como objeto de consideração algumas das constatações que foram destacadas pelo GTAA. Elas dizem respeito à produção acadêmica, de um lado, e, de outro, às condições da própria avaliação e aos apontamentos para o seu aperfeiçoamento.

O modelo de Análise e Dependência dá destaque a duas constatações resultantes da análise estatística. A primeira diz respeito à capacitação de recursos humanos.

Houve avanço na Unesp em termos de capacitação docente e carreira acadêmica, com o crescimento do número de titulados em todas as áreas. Colocam-se à frente os departamentos da área de $\mathrm{Ci}$ ências Biológicas, seguida pelas áreas de Ciências Exatas, Ciências Agrárias e Saúde. Embora com média menor, também houve crescimento na área de Ciências Humanas. Esta, por sua vez, apresentou, junto com a área de Ciências Exatas, crescimento maior que as demais na titulação de mestrado.

Essa evolução observada pode, no entanto, ser interpretada como uma passagem de mestres a doutores, reforçando

\begin{tabular}{l|c|c}
\multicolumn{1}{c|}{ Área } & 1991 & 1992 \\
Ciências Agrárias e da Saúde & 59 & 59 \\
Ciências Biológicas & 34 & 35 \\
Ciências Humanas & 57 & 59 \\
Ciências Exatas & 45 & 45 \\
\hline Total & 195 & 198 \\
\hline
\end{tabular}


essa evolução de um ano para o outro. Sobre essa ordenação dos resultados sugeriu-se ao Cepe a reflexão sobre uma política e medidas a serem adotadas para atender à especificidade da formação e titulação dos docentes na área das Ciências Humanas.

A segunda constatação refere-se ao ensino de graduação e pós-graduação.

Fica clara a existência de duas tendências relativas às atividades de ensino e de pesquisa e que estão presentes nas quatro áreas que agrupam os departamentos: uma voltada à formação de profissionais para o mercado de trabalho e de docentes para o ensino de 1 으 e 20 graus e para a extensão e serviços à comunidade; outra, voltada à pós-graduação e pesquisa.

Em face dessa constatação, cabe aos departamentos e ao Cepe questionar se esta dicotomia, que pode dividir a Unesp em "duas universidades", corresponde ao futuro que se quer construir desde hoje para ela. Esse tipo de indagação deve suscitar naqueles que atuam no ensino, na pesquisa e no órgão central que delibera sobre políticas para esses dois tipos de atividades, a reflexão, a discussão e a elaboração de políticas que direcionem o exercício do ensino na graduação e na pós-graduação conjugados à pesquisa para os rumos que se quer para a Unesp.

O modelo Hierárquico Dinâmico, por sua vez, também aponta para dois tipos de constatação de natureza diversa:

A primeira traduz-se na produção acadêmica pequena ou grande dos departamentos, resultante do desempenho das funções de ensino, pesquisa e extensão, quando relacionada à disponibilidade de recursos docentes.

A segunda põe em evidência limitações para análise dos resultados do ajustamento do modelo nesses dois primeiros anos, dentre as quais se destacam: a escolha das variáveis e as incorreções nos dados.

No primeiro caso, sugere-se a revisão da lista dos indicadores, sua ponderação, fazendo nela a inclusão de "medidas da qualidade do ensino, taxas de evasão e reprovação, a variância das notas e indicadores da satisfação ou insatisfação do corpo discente com o ensino de cada disciplina" (Universidade Estadual de São Paulo, 1993, p. 55). No que diz respeito à pesquisa e à extensão, a relevância científica e o alcance social da produção dos departamentos também devem ser objeto de avaliação.

Nesse sentido, a título de sugestão, o GTAA anexou ao Relatório Final uma primeira lista de itens relativos ao desempenho do ensino da pesquisa e extensão que, num momento posterior, podem ser analisados pelos departamentos como ponto de partida para a elaboração de uma proposta de avaliação qualitativa.

As incorreções nos dados, por sua vez, revelam as limitações dos mecanismos de sua coleta, como, por exemplo, os erros de cálculo e variações de critério que resultaram na perda de confiabilidade de indicadores importantes.

Em termos de apontamentos para o aperfeiçoamento dos modelos estatísticos, o GTAA é enfático quando afirma que “... não obstante o sistema de coleta e tratamento de dados empregado nesta fase inicial tenha se mostrado capaz de lidar com o volume de dados gerado por uma extensa lista de variáveis, para que o sistema de avaliação produza seus melhores resultados, a longo prazo, deve ser melhor estruturado". Isso pode ser obtido com relativa facilidade através de maior automação dos mecanismos de coleta e

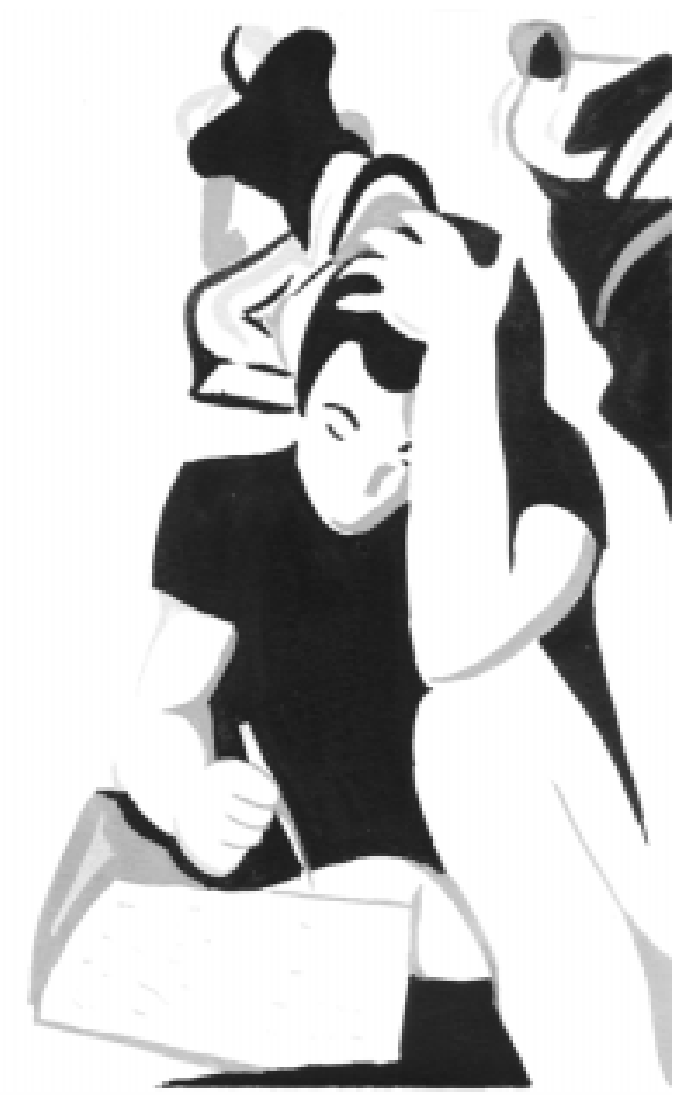


crítica dos dados, integração com outros sistemas de informação sobre produção acadêmica já consolidados e a implantação de uma estrutura permanente de tratamento da documentação.

Fechando o relatório dessa primeira avaliação, o GTAA reafirma que a divulgação dos seus resultados não objetiva "sustentar qualquer posição final mas, pelo contrário, suscitar maior discussão dos procedimentos pelos quais se deve aperfeiçoar o processo de avaliação".

\section{A avaliação institucional da Unesp como processo contínuo e cumulativo: o período de 1991 a 1994}

\section{A evolução do processo avaliatório da Unesp}

Orientada pelos mesmos objetivos e princípios gerais formalizados em 1992, na fase do planejamento do processo, a abertura de um novo ciclo avaliatório ocorreu em março de 1995.

Como processo em construção contínua, esse novo ciclo se delineou, levando em conta as indicações e recomendações registradas no relatório do período 19911992, buscando o aperfeiçoamento da avaliação seja pela confirmação, seja pela reformulação ou mudança de seus indicadores, seu método e suas estratégias.

O período considerado para a coleta de dados do novo ciclo cobriu os anos de 1991, 1992, 1993 e 1994, atendendo ao princípio da cumulatividade progressiva dos resultados das atividades acadêmicas.

É essa cumulatividade que permite, através de ajustamento estatístico do Modelo Hierárquico Dinâmico, chegar-se à "geração de padrões objetivos de comparação" intradepartamento em cima dos "coeficientes de produção dos grandes agregados de ensino, pesquisa e extensão (...) estimados para o próprio departamento a partir dos anos anteriores" (Sant'Anna, 1996, p. 1-3).

Respeitando o princípio da especificidade de cada departamento e de suas atividades acadêmicas, o modelo não intenciona a comparação interdepartamental para classificá-los em termos de melhor ou pior, mais eficiente ou menos eficiente, como poderia ocorrer numa avaliação meramente somatória com inten- ções meritocráticas. É, portanto, a evolução de cada departamento que o processo avaliatório quer captar e descrever.

De outra parte, é verdade que a configuração gráfica dos resultados das diferentes áreas de conhecimento no Relatório Final poderá induzir a uma leitura comparativa interdepartamental. Há que se reconhecer, no entanto, a importância dessa ampla visão do desempenho e da produtividade acadêmica dos departamentos, pois é por eles que se apreende o estado atual da universidade como um todo, no que diz respeito às suas funções-fim. É também pelos departamentos que, tomando-se cada um na sua dinâmica própria ou visualizando-os no conjunto de suas ações e nas suas tendências, vai sendo construída a autoconsciência institucional necessária à explicitação da identidade da Unesp.

A análise do ajustamento estatístico permitirá, também, que se tomem como objeto de estudo alguns departamentos com desempenho discrepante, quando comparado com a sua performance anterior e com os coeficientes técnicos de que dispõem para previsão de produtividade. O objetivo deste estudo vai além dessa constatação da dinâmica dos resultados por apontar aspectos qualitativos do desempenho que devem ser considerados e por buscar nesses departamentos sugestões de medidas para o aprimoramento ou a melhoria do desempenho com reflexos qualitativos nos resultados.

É essa, também, a função do modelo estatístico da Análise de Dependência, quando põe em evidência semelhanças e diferenças entre departamentos, revelando tendências que vão se definindo pelas atividades predominantes em cada um deles ou nas áreas de conhecimento.

O propósito desse modelo, como o do Modelo Hierárquico Dinâmico, é oferecer informações que possam suscitar no interior dos departamentos a reflexão e o debate, que resultem no aprofundamento do autoconhecimento para a elaboração de estratégias ou planos que aprimorem ou melhorem a instituição Unesp no cumprimento de sua função social.

Em razão da sintonia dos propósitos e princípios que orientam os dois modelos, com os objetivos e princípios da avaliação em processo e pelos primeiros resultados obtidos pela sua aplicação nos anos de 1991 e 1992, o Cepe manteve o mesmo sistema metodológico para a ava- 
liação institucional no período que incorpora os anos de 1993 e 1994.

Essa decisão, no entanto, não implicou o fechamento desse sistema à adoção de outros procedimentos a serem utilizados na análise dos dados, com o propósito de explicitar e realçar a interface quantidade-qualidade da produção acadêmica.

Caminhando nessa direção, o sistema metodológico incluiu um tratamento estatístico complementar, a Análise de Freqüência, para uma interpretação qualiquantitativa de alguns indicadores das funções de ensino, pesquisa e extensão, aos quais foi atribuída prioridade $\left(P_{1}\right)$ pelos departamentos.

O resultado desse tratamento estatístico indicou a relação maior ou menor entre os indicadores mais valorizados pelos departamentos e a freqüência com que eles comparecem na sua produção acadêmica. Tomem-se como exemplos as publicações. O que prevalece: aquelas feitas em periódicos com referees $\left(P_{1}\right)$ ou artigos publicados em revistas não indexadas ou não especializadas $\left(\mathrm{P}_{2}\right)$ ou ainda a publicação de notas e resenhas $\left(\mathrm{P}_{3}\right)$ ?

A leitura dos gráficos que mostram esse tipo de relação levará, certamente, os departamentos a uma interpretação crítica e, por conseqüência, a uma tomada de posição em relação a desempenhos futuros.

\section{A comissão permanente de avaliação acadêmica}

A substituição do GTAA, de caráter temporário, pela Comissão Permanente de Avaliação Acadêmica (CPAA), ao mesmo tempo em que atende à recomendação do Relatório Final do período 1991-1992, atesta o estágio de consolidação da avaliação institucional da Unesp como processo permanente e contínuo.

A criação dessa comissão se deu conforme deliberação do C.O. em 15/12/94 e pela Portaria no 41 de 20/2/95 do reitor da Unesp. Sob a presidência do vice-reitor, professor doutor Antonio Manoel dos Santos Silva, a comissão foi integrada por: três docentes representantes da Comissão Central de Pós-Graduação (CCPG), Comissão Central de Graduação (CCG) e Comissão Central de Extensão Universitária (CCEU), um docente representante titular e um suplente de cada uma das áreas de conhecimento, definidas agora em número de oito, como desdobramento das Ciências Exatas, Biológicas e Humanas; três representantes discentes titulares e seus suplentes para cada uma dessas três grandes áreas; dois consultores especialistas em avaliação, dois consultores externos em estatística e um especialista em processamento de dados. A comissão passou a contar com um grupo de apoio da reitoria, constituído por uma assessora da presidência, uma secretária e uma representante de cada Pró-Reitoria: de Graduação, de PósGraduação e de Extensão.

Por essa composição, vê-se que o Cepe ampliou o espaço de participação democrática na condução do processo avaliatório, fazendo da CPAA um núcleo representativo da diversidade do trabalho acadêmico e capaz de entender e atender à complexidade de relações que ela engendra no interior das unidades, e destas com os órgãos centrais da Unesp. Em relação a estes últimos, a CPAA mantém contato com as Pró-Reitorias de Graduação, de Pós-Graduação e Pesquisa e de Extensão, buscando a sintonia entre os trabalhos de avaliação e as políticas de ação desses órgãos. Vinculada ao Cepe, o CPAA tem a função de conduzir o processo avaliatório em todas as suas fases, desde a preparatória até a elaboração do relatório final, passando pela execução e pelo tratamento dos dados, num processo de comunicação permanente com os departamentos objeto da avaliação. Embora atuando sem função deliberativa, a CPAA constitui-se o canal formal para fazer chegar ao Cepe sugestões e recomendações para o aperfeiçoamento do processo avaliatório, bem como relatar-lhe os resultados com indicações que suscitem a reflexão e subsidiem a tomada de decisões sobre políticas ou projetos para o aperfeiçoamento da universidade.

\section{A revisão dos indicadores: o Encontro de Ibitinga}

Uma das recomendações do Relatório Final da Avaliação do período 19911992 dizia respeito à necessária revisão dos 110 indicadores de produtividade acadêmica aprovados anteriormente pelo Cepe, de modo a adequá-los mais estreitamente às especificidades das áreas de conhecimento.

Sob a coordenação do CPAA, essa revisão foi feita pelos chefes dos departamen- 
tos e representantes discentes reunidos, segundo a área de conhecimento que integravam, em encontros realizados na Pousada Ibitinga, da Cesp, nas seguintes datas: 25 e 26/4/95 - Ciências Humanas; ${ }^{2} \mathrm{Ci}$ ências Sociais Aplicadas, Lingüística, Letras e Artes; 27 e 28/4/95 - Ciências Exatas e da Terra, Engenharias; 3 e 4/5/95 - Ciências Biológicas Básicas, Ciências Agrárias e Veterinárias, Ciências da Saúde.

Participaram desses encontros aproximadamente 194 departamentos, do total de 207 existentes.

Com o Encontro de Ibitinga (como ficou conhecido), a avaliação institucional da Unesp abriu-se à participação mais direta dos departamentos pela presença de seus chefes e alunos, tendo por trás suas respectivas unidades, permitindo, assim, que o clima social do processo avaliatório atingisse a sua plenitude democrática.

Se na avaliação realizada no período de 1991-1992 a participação dos departamentos, na maioria das vezes, se fez pelo envio, via malote, de documentos com propostas e sugestões para a definição dos indicadores, agora esses departamentos, pelas pessoas de seus chefes e alunos, se reuniam para revê-los e, à viva voz, discutir a sua pertinência às respectivas áreas e o valor relativo de cada um deles.

O documento básico, objeto de análise pelos grupos, trazia a lista dos 110 indicadores precedida de uma breve descrição do processo avaliatório em curso, de seus princípios e objetivos e de seu sistema metodológico. A orientação passada pela CPAA deixava a critério de cada área:

1) A introdução de novos indicadores relevantes, a eliminação de indicadores considerados não relevantes, a alteração da redação ou fusão de indicadores numa nova proposição.

2) A atribuição de prioridades, variando de 1 a 3 e de pesos de 1 a 10 a cada indicador.

3) A revisão dos pesos atribuídos pelo Cepe aos blocos de indicadores relativos a: 1) Identificação do Departamento; 2) Atividades Relativas à Formação; 3) Atividades de Pesquisa; 4) Atividades de Ensino; 5) Atividades de Extensão; 6) Atividades Administrativas.

Em cada grupo, um membro da CPAA representante da área coordenou os trabaIhos, assegurando a participação de todos e a objetividade das discussões.
Em conseqüência da liberdade da palavra, as discussões foram explicitando a diversidade do fazer acadêmico entre departamentos diferentes, porém tendo em comum uma mesma área de conhecimento. Essa diversidade foi expressa pela relevância maior ou menor por eles atribuída a certos indicadores ou blocos de atividades comuns a todos. Para além das características próprias de cada departamento, há que se considerar também as concepções de universidade e, por conseqüência, a importância conferida a certas atividades do ensino, da pesquisa e extensão, nem sempre convergentes entre os participantes das áreas, influindo na revisão e valorização dos indicadores. Entretanto, foi também essa ampla discussão que encaminhou os representantes de cada agrupamento à tomada de decisões equilibradas de modo a garantir, no final, a unidade das áreas respeitando a diversidade dos departamentos que as compõem.

Foi nesse contexto de diversidade que a ampla discussão propiciada pelo encontro levou os departamentos a encontrarem na área como denominador comum a unidade explicitada, seja por unanimidade, seja pelo consenso ou pela voz da maioria, na escolha e valoração dos indicadores aprovados por todos.

Esses indicadores já não eram mais os mesmos 110 apresentados no documento-base e também não se repetiam inteiramente em número, conteúdo, forma e valor atribuídos às oito áreas de conhecimento. Numa rápida ilustração com o número total de indicadores, eles variaram nas diferentes áreas, de 103 a 126 , com incidências maiores pela ordem no Bloco III, referente à Pesquisa, variando de 27 a 52, e no Bloco IV, referente ao Ensino, com variação de 16 a 31. O Bloco V, dedicado à Extensão, alcançou menores números de indicadores, variando de 13 a 16 . O total mais alto de indicadores foi definido pela área de Lingüística, Letras e Artes com o número de 126 e o mais baixo, com 103, pelas áreas de Ciências Humanas e Engenharias.

Da importância desse evento destaco três aspectos, que considero de relevância maior:

O primeiro foi a oportunidade que tiveram os seus participantes de fazer uma leitura coletiva e crítica do universo de ações que justificam a existência de

\footnotetext{
2 Posteriormente, os departamentos cujas funções de ensino, pesquisa e extensão estão diretamente vinculadas à Educação foram desligados das Ciências Humanas e passaram a integrar uma nova área (Educação) sob a justificativa de seus membros possuírem características próprias a serem consideradas na revisão dos indicadores.
} 
uma universidade e, como profissionais intelectuais, emitirem sobre elas juízos de valor.

O segundo foi a convergência das atividades e dos resultados do encontro para um objetivo prioritariamente definido para a avaliação da Unesp, qual seja, "a construção de uma autoconsciência institucional e de uma identidade explícita". Como participante, pude observar no decorrer dos trabalhos o "caminhar" dos grupos na direção desse objetivo. Por isso, se é válido afirmar que o autoconhecimento no nível das áreas avançou, é também legítimo dizer que essa autoconsciência se expandiu na visão de totalidade da Unesp, pois que toda a análise crítica dos indicadores e a sua proposição final teve como referencial maior essa instituição na sua totalidade.

Finalmente, destaco um terceiro aspecto da maior relevância para o êxito do processo avaliatório: o envolvimento total dos participantes nos trabalhos realizados em dois dias completos para cada área, evidenciando o interesse e a seriedade com que assumiram essa fase da avaliação.

\section{A coleta de informações}

Aprovados pelo Cepe, os indicadores revistos no Encontro de Ibitinga foram organizados em oito planilhas diferentes correspondendo às áreas de conhecimento e encaminhadas aos departamentos acompanhadas dos respectivos manuais de instruções para o seu preenchimento. Esse trabalho foi feito cuidadosamente pelo Grupo de Apoio Técnico da CPAA, que se empenhou em imprimir ao material uma linguagem simples, clara e objetiva.

Um canal de contatos com a CPAA foi aberto por telefone com a assessora do presidente da comissão. Esses contatos foram da maior importância, seja pelo fato de permitirem o aclaramento de dúvidas e a identificação de indicadores com dificuldades comuns de resposta que pediam reorientações da CPAA, seja pela estratégia adotada nas unidades, de promover discussões entre chefes e secretárias dos departamentos para resolver dificuldades de interpretação comuns e racionalizar as consultas à comissão.

Devolvidas à CPAA, as planilhas preenchidas passaram por uma leitura pelos representantes das áreas, feita para avaliar a congruência dos dados, possíveis in- correções ou informações incompletas. O resultado dessa leitura foi organizado pelo grupo de apoio técnico e, no caso de a planilha não apresentar incorreções, o departamento remetente recebeu uma notificação da comissão sobre a competência com que participou dessa fase da avaliação. Quando correções se fizeram necessárias, as planilhas voltaram aos departamentos em questão com instruções para as correções devidas.

\section{As visitas aos departamentos e a finalização dos trabalhos}

A fase de coleta de dados completouse com as visitas da CPAA, pelos seus representantes das áreas, aos departamentos, promovendo com eles um encontro dialógico com o propósito de fazer esclarecimentos pontuais e trocas de idéias sobre certos indicadores, seja sobre a clareza de sua formulação, seja quanto à dificuldade para respostas mais completas e precisas, seja ainda quanto à relevância de certos indicadores e à importância da avaliação institucional.

Em todos os departamentos, a receptividade à CPAA foi boa. Se de início percebeu-se uma certa expectativa de que as visitas tivessem algum caráter de fiscalização, essa impressão se desfez com o clima informal de troca de idéias interpares, em favor do aperfeiçoamento da coleta de dados.

O que ficou patente nessas visitas foi a seriedade com que os departamentos se empenharam no fornecimento dos dados, seja da parte dos docentes, seja da parte das secretárias que atuaram como "pivots" permanentes na coleta e ordenação dos dados e no preenchimento cuidadoso das planilhas. No dizer de um dos membros da CPAA, "já se pode ressaltar o papel pedagógico da avaliação na Unesp".

Nas impressões de outros, "uma cultura de avaliação" aflora com o reconhecimento da sua importância, com a participação consciente, pela crítica que contribui para o aperfeiçoamento na definição dos indicadores, pela expressão de interesse pela questão da avaliação da qualidade do desempenho e pela preocupação com a utilização dos resultados da avaliação em curso. Esse "amadurecimento" dos departamentos em relação ao processo avaliatório estaria sendo favorecido pelo clima demo- 
crático em que transcorreram as relações entre a CPAA e os departamentos.

Terminada essa fase, a comissão passou a ocupar-se da análise quantiqualitativa dos dados levantados e da redação do relatório do ciclo de avaliação da Unesp que encampou o período de 1991-1994.

$\mathrm{O}$ encaminhamento das atividades nessa última fase levaram a conclusões que, não sendo definitivas, suscitarão o questionamento, a reflexão e o debate no interior das unidades propiciando, ao mesmo tempo, o amadurecimento da autoconsciência institucional e a explicitação de sua identidade, necessárias à tomada de decisões que favoreçam a implementação de um projeto de universidade definido coletivamente.

É este o objetivo da avaliação institucional da Unesp.

\section{Considerações finais}

Chegando ao final deste artigo, que teve como interesse maior descrever a trajetória metodológica de construção coletiva do processo de avaliação da Unesp, posso, de imediato, afirmar que, no seu decorrer, os trabalhos convergiram para os objetivos iniciais acima reafirmados.
Mediante um trabalho coletivo que ultrapassou a mera quantificação do que foi produzido, os departamentos puderam refletir e avaliar as suas funções de ensino, pesquisa e extensão e serviços em suas múltiplas implicações. O exercício da análise totalizada permitiu-Ihes a leitura crítica da produção e do desempenho no período 1991-1994 e fazer projeções para o futuro, tendo em vista as peculiaridades da Unesp como universidade constituída por muitos campi, com potencialidade para corresponder à diversidade regional do Estado de São Paulo e responder às demandas da sociedade brasileira com as mudanças de ordem econômica, sociais e de valores culturais presentes nesta passagem do século.

Finalmente, como processo permanente, a avaliação da Unesp busca o seu próprio aperfeiçoamento. Nessa direção, o exercício da meta-avaliação posta em prática, desde o início, pela CPAA, com feedback dos departamentos, permitiu identificar e situar dificuldades e falhas de comunicação, de desempenho e de procedimentos, bem como fazer as retificações necessárias e possíveis para a elevação da qualidade do processo avaliatório.

\section{Referências bibliográficas}

CORDEIRO, J. A. Análise de dependência : uma metodologia para análise de dados multivariados discretos. 1993. (mimeo).

CROMBACH, L. J. et al. Toward reform of program evaluation. San Francisco : JosseyBass, 1980, apud NEVO, D. The conceptualization of educational evaluation : an analytical review of the literature. Review of Educational Research, v. 53, n. 1, p. 117-128, spring, 1983.

DIAS SOBRINHO, J. Universidade : processos de socialização e processos pedagógicos. In: BALZAN, N. C., DIAS SOBRINHO, J. (Org.). Avaliação institucional : teoria e experiências. São Paulo : Cortez, 1995.

DORNBUCH, S. M., SCOTT, W. R. Evaluation and the exercise of authority. San Francisco : Jossey-Bass, 1975, apud NEVO, D. The conceptualization of educational evaluation : an analytical review of the literature. Review of Educational Research, v. 53, n. 1, p. 117-128, spring, 1983.

GRAMSCI, A. A concepção dialética da História. Rio de Janeiro : Civilização Brasileira, 1966.

HABERMAS, J. A idéia de Universidade : processos de aprendizagem. Revista Brasileira de Estudos Pedagógicos, Brasília, v. 74, n. 176, p. 111-130, 1993, apud DIAS SOBRINHO, J. Universidade : processos de socialização e processos pedagógicos. 
In: BALZAN, N. C., DIAS SOBRINHO, J. (Org.). Avaliação institucional : teoria e experiências. São Paulo : Cortez, 1995, p. 15-36.

HOUSE, E. R. The politics of educational innovation. Berkeley, CA : Sage, 1974, apud NEVO, D. The conceptualization of educational evaluation : an analytical review of the literature. Review of Educational Research, v. 53, n. 1, p. 117-128, spring, 1983.

NEVO, David. The conceptualization of educational evaluation : an analytical review of the literature. Review of Educational Research, v. 53, n. 1, p. 117-128, spring, 1983.

OLIVEIRA, E. F. T. O ensino das disciplinas instrumentais no currículo de graduação em Biblioteconomia. Marília, 1996. Dissertação (Mestrado) - Universidade Estadual Paulista. Campus de Marília.

PATTON, M. Q. Utilization focused evaluation. Beverly Hills, CA : Sage, 1978, apud NEVO, $D$. The conceptualization of educational evaluation : an analytical review of literature. Review of Educational Research, v. 53, n. 1, p. 117-128, spring, 1983.

SANT'ANNA, A. A modelagem da produtividade acadêmica como instrumento de promoção da qualidade da Unesp. São Paulo, 1996. (mimeo).

SANTOS FILHO, J. C. Pesquisa quantitativa versus pesquisa qualitativa : o desafio paradigmático. In: SANTOS FILHO, J. C., GAMBOA, S. S. (Org.). Pesquisa educacional : quantidade-qualidade. São Paulo : Cortez, 1995. p. 13-59.

SCRIVEN, M. The methodology of evaluation. Chicago : Rand McNally, 1967, apud NEVO, D. The conceptualization of educational evaluation : an analytical review of literature. Review of Educational Research, v. 53, n. 1, p. 117-128, spring, 1983.

SPÓSITO, Maria Encarnação B. Novas formas de atuação. Jornal da Unesp, v. 15, n. 102 , p. 2, abr. 1996.

STUFFLEBEAM,D. L. An introduction to the PDK Book. In: STUFFLEBEAM, D. L. et al. Educational evaluation and decision-making. Itaska, IL : Peacock, 1971.

. The relevance of the CIPP evaluation model for educational accoutability. SRIS. Quartely, n. 5, p. 3-6, 1972, apud NEVO, D. The conceptualization of educational evaluation : an analytical review of the literature. Review of Educational Research, v. 53, n. 1, p. 117-128, spring, 1983.

THIOLLENT, M. J. M. Aspectos qualitativos da metodologia da pesquisa com objetivos de descrição, avaliação e reconstrução. Cadernos de Pesquisa, v. 49, p. 45-50, maio 1984, apud OLIVEIRA, E. F. T. O ensino das disciplinas instrumentais no currículo de graduação em Biblioteconomia. Marília, 1996. Dissertação (Mestrado) Universidade Estadual Paulista. Campus de Marília.

UNIVERSIDADE ESTADUAL PAULISTA. Avaliação acadêmica dos departamentos : relatório final, 1991 e 1992. Marília, 1993. v. 1., p. 1-191

. Despacho n. 45/93-Cepe/SG. Constituição do Grupo de Trabalho de Avaliação Acadêmica (G.T.A.A.). Universidade Estadual Paulista, São Paulo, 18.03.1993 (conforme processo 2002/50/03/89-Runesp).

. Portaria Unesp n. 41/95. Cria a Comissão Permanente de Avaliação Acadêmica. Diário Oficial do Estado de São Paulo, São Paulo, 21.02.1995. p. 48.

Recebido em 31 de março de 1998.

Thereza Marini, membro do Grupo de Trabalho de Avaliação Acadêmica (GTAA) da Universidade Estadual Paulista (Unesp) em 1993, foi assessora da Comissão Permanente de Avaliação Acadêmica (CPAA) dessa universidade até 1997. 


\section{Abstract}

The article analyses the institutional evaluation process of Universidade Estadual Paulista (Unesp) underlying the methodology of its development. Within a democratic relation network the evaluation was carried out through a process that describes and assess those activities that are relevant for both the functions and the goals of the institution, in view of its resources and social-historic context. The work starts evaluating 207 departments that make up the Unesp, classified into three groups of research and teaching (Human and Biology Sciences, Tecnology). The evaluation created "an especific, continuous and cyclical activity that involves different phases and operations" in its 15 campi and 24 university units, during the period 1991-1994. The information was gotten from indicators selected by the university units departments that took into consideration the objectives and principles which were previously defined. This Unesp evaluation has become helpful for the development of a process of continuous reflexion and debate that aims to build up an institutional self-conciousness and an explicit identity as well as providing finantial support for taking decisions that promote the implementation of a university project that is defined collectively.

Key-Words: institutional evaluation; indicators; Committee of Permanent Academic Evaluation (CPAA); statistical models. 